\title{
Assessment of resting energy demand and body composition in oncological patients undergoing partial resections of the liver
}

\author{
Anna Ukleja ${ }^{1}$, Marta Andrzejewska ${ }^{2}$, Michał K. Skroński ${ }^{2}$, Michał Ławiński $^{2}$, Dariusz Włodarek ${ }^{3}$, Michał Korba $^{2}$, \\ Paweł Nyckowski², Maciej Słodkowski ${ }^{2}$ \\ ${ }^{1}$ Department of Clinical Dietetics, Medical University of Warsaw, Warsaw, Poland \\ 2Department of General, Gastroenterological, and Oncological Surgery, Medical University of Warsaw, Warsaw, Poland \\ ${ }^{3}$ Department of Dietetics, Warsaw University of Life Sciences, Warsaw, Poland
}

Gastroenterology Rev 2019; 14 (1): 62-68

DOI: https://doi.org/10.5114/pg.2019.83427

Key words: bioelectric impedance, metabolism, indirect calorimetry.

Address for correspondence: Michat tawiński MD, PhD, Department of General, Gastroenterological, and Oncological Surgery,

Medical University of Warsaw, 61 Żwirki i Wigury St, 02-091 Warsaw, Poland, phone: +48 22599 22 57, e-mail: michal-lawinski@wp.pl

\begin{abstract}
Introduction: The metabolism of the body is a complicated process. The most important organ of the organism that affects the intensity of changes is the liver. An effective treatment method of primary and metastatic tumours is a partial resection of the organ. The analysis of changes in the body composition of patients undergoing this type of treatment allows identification of problems coexisting with the underlying disease.

Aim: To evaluate changes in the parameters of body composition and the amount of resting metabolism.

Material and methods: The study group consisted of 87 patients who underwent resection of changes in the liver or thermoablation of focal lesions during hospitalisation.

Results: Analysis of the data showed that the surgical intervention contributes to a statistically significant $(p<0.05)$ decrease in the value of the phase angle. A significant increase was noted within the extra cellular water content. The amount of resting metabolism in the postoperative period did not differ significantly; however, there was an upward trend in women and a downward trend in men.

Conclusions: Surgical resection of lesions aimed at extending the survival of patients are performed more and more often, while the consequences of these operations are not sufficiently known. The adverse effect of resection treatments on body composition parameters, mainly imaged by decreasing the phase angle value, should be minimised. Effects on metabolism remain ambiguous because no significant changes have been demonstrated in the postoperative period.
\end{abstract}

\section{Introduction}

The neoplastic changes detected at the appropriate stage in the liver, which is the organ responsible for the metabolism of macronutrients, can be cured by, among others, radical resection. In the vast majority of patients, these tumours form in the initially unchanged pathologically and fully functional parenchyma due to translocation in the course of carcinogenesis. The most common primary location is adenocarcinoma of the large intestine, for which the incidence over the last decades has an unstoppable upward trend. Other causes of hepatic proliferation include: chronic inflammation involving a major part of the parenchyma in the course of, for example, advanced alcoholic disease, use of hormonal contraception by women, and hepatitis $B$ virus (HBV) and hepatitis C virus (HCV) infection $[1,2]$.

A surgical procedure involving partial resection of the liver is associated with the occurrence of physiological reactions resulting from mechanical tissue damage and removal of the efficient part of the organ. The assumption of an effective operation of this type is to leave an adequate amount of active parenchyma, which will ensure organ capacity within the limits of standards adopted for the general population and initiate regeneration processes in the shortest possible time. Perioperative management should include activities to support the body, which will improve the recovery. Such 
activities include, for instance, proper fluid therapy, and it is also important to personalise the supply of nutrients adapted to the energy needs [3].

The resting metabolic rate of patients in the perioperative period can be measured using indirect calorimetry or calculated using equations developed taking into account variables such as: anthropometric measurements, age, sex, clinical status, and others, but with varying degrees of accuracy. The choice of the optimal method for the studied group of patients is a complex issue including the selection of variables that have a significant impact on the demand and at the same time are easy to obtain.

The incidence of liver malignant tumours in Poland, according to the estimates of the International Agency for Research on Cancer (IARC), will amount to 2211 new cases in 2020, which will constitute an increase of approximately $11 \%$ compared to the data for the year 2012. Mortality will also increase: in 2020 it will amount to 2332 deaths due to liver cancer (an increase of about $13 \%$ ) [4].

\section{Aim}

The aim of the study was to evaluate changes in the parameters of body composition and the amount of resting metabolism.

\section{Material and methods}

The measurements were performed at the oncological surgery clinic in 110 patients referred for planned resection of liver tumours, from September 2017 to July 2018. The basis for exclusion from further analyses in the study group were preoperative or intraoperative circumstances such as the inability to carry out effective surgical procedure due to tumour dissemination with unpredictable course dynamics or unfavourable location of changes from the surgical point of view, haemodynamic destabilisation, or death. The data of hospitalised subjects, whose condition and radiological and biochemical assessment allowed for surgery, were taken into account. Patients gave written, informed consent to participate in a clinical trial. The condition was a violation of the continuity of the liver parenchyma in order to remove the tumour together with a safe, histopathologically unchanged margin or to perform thermoablation of focal lesions. Finally, 87 people were examined.

In the study group, the median age was 63 years (min.: 22, max.: 80 ), and $53 \%$ of the subjects were women whose median age was slightly lower at 60.5 years (min.: 22, max.: 77). The age of men was in accordance with the normal distribution; therefore, the average was calculated, which amounted to 64.07 \pm 8.40 years. Among the respondents, $43 \%$ (37 patients) were in the age group between 60 and 70 years, being the largest group.

Based on anthropometric measurements, the mean waist-hip ratio (WHR) was calculated, which was 0.96 \pm 0.09 (in men it was: $1.03 \pm 0.07$, in women $0.90 \pm 0.06$, $p<0.0001)$ and the mean body mass index (BMI), which before surgery was $26.92 \pm 4.56 \mathrm{~kg} / \mathrm{m}^{2}$ and after surgery was $26.64 \pm 4.43 \mathrm{~kg} / \mathrm{m}^{2}$. The mean arm circumference in the study group was $31.35 \pm 4.01 \mathrm{~cm}$ (in men: $32.87 \pm 3.51 \mathrm{~cm}$, in women $29.92 \pm 3.96 \mathrm{~cm}, p=0.0016$ ).

Metastatic tumours were the cause of $77 \%$ of the total resection. The most common primary location was the large intestine (in $80.65 \%$ of men and in $66.67 \%$ of women). Other sources of metastatic changes were: bile ducts, gallbladder, duodenum, eye, and gastrointestinal stromal tumors (GIST), and there were also single observations for metastases from: stomach, cervix, ovary, lung, breast, kidney, and sarcoma. The remaining reasons for surgery were: hepatocellular carcinoma (in 9 patients), focal nodular hyperplasia (in 4 patients), and tumours derived from intrahepatic bile duct cells (3 cases).

The following types of surgical procedures were performed: hemihepatectomy, segmentectomy, focal resection, and thermoablation of focal lesions. The most frequently performed types of procedures were hemihepatectomies, constituting $41.46 \%$ of operations in men and $34.78 \%$ in women; an extended procedure involving the addition of another type of surgery was performed in 11 patients. Operations involving the removal of a single segment or selected segments were conducted in total in $26.83 \%$ of men and in $32.61 \%$ of women, of whom 11 required extended. Resections involving the non-anatomical part of the segment concerned $24.39 \%$ of men and $30.44 \%$ of women, of which four required widening. Exclusive thermoablation was used in four cases. The average number of resected segments was $3.07 \pm 1.31$, for segmentectomy it was $1.73 \pm 0.68$, and for hemihepatectomy it was $4.12 \pm 0.41$. Based on the obtained histopathological results, the sum of tumour diameters in the recovered material was on average $87.50 \pm 47.21 \mathrm{~mm}$ for hemihepatectomies, 61.18 $\pm 37.25 \mathrm{~mm}$ for segmentectomy, and $36.68 \pm 23.23 \mathrm{~mm}$ for focal resections.

All measurements were made the day before surgery and on the seventh day after surgery. Measurements included: laboratory tests, anthropometric tests (perimeter of arm, waist and hip), BMI, measurement of resting energy demand with the Fitmate GS device (Cosmed, Italy) - canopy version and body composition measurement with AKERN BIA 101 Anniversary analyser by the octapolar method. The tests were carried out in a semi-recumbent position, and the average ambient 
temperature was $25.5^{\circ} \mathrm{C}$. A minimum three-hour break was established since the last meal and stimulants.

The study was positively appraised by the Bioethics Committee of the Medical University of Warsaw and was carried out in accordance with the guidelines of the Helsinki Declaration updated in 2013.

Raw physical data from the BIA analyser were interpreted after being inserted into the Bodygram PRO 3.0 program. The obtained values of resting metabolism were standardised due to the actual body weight. In order to assess the normality of distribution of quantitative traits, the Shapiro-Wilk test was carried out.

\section{Statistical analysis}

Statistical analysis was performed using the Statistica $13 \mathrm{PL}$ program (StatSoft Inc., USA) using the $t$-test for variables with normal distribution and the Wilcoxon signed-rank test for nonparametric variables; the interrelations between variables were examined by multiple regression and Friedman's test for the influence of the studied traits. A $p$-value $<0.05$ was considered statistically significant.

\section{Results}

Following the surgical trauma, the phase angle (PA) value decreased by $0.68^{\circ}$ on average. The average reduction was higher in women $\left(0.78^{\circ}\right)$ than in men $\left(0.56^{\circ}\right)$. There was also a significant reduction in cellular mass (BCM), muscle mass ( $M M)$, and fat mass (FM). The total water content (TBW) did not change significantly; however, there was a shift of water from the intra-site (ICW) to the extracellular space (ECW); the results are presented in Table I.

Median resting metabolic rate (RMR) before surgery was $1368 \mathrm{kcal} /$ day (min.: 738, max.: $2480 \mathrm{kcal}$ ) in men, the average was $1674.47 \pm 260.83 \mathrm{kcal} /$ day, and in women $1242.57 \pm 147.56 \mathrm{kcal} /$ day. These values did not change significantly in the postoperative period $(p=0.4387$, median $(M)=1396 \mathrm{kcal} /$ day, $\min .:$ 826; $\max$ : 2146; males: $p=0.0978, A v=1609.13 \pm 225.91 \mathrm{kcal} /$ day; females: $p=0.4583, \mathrm{Av}=1260.2 \pm 163.06 \mathrm{kcal} /$ day). After surgery, there was a significant reduction in RMR calculated from the Harris-Bendict formula (HB) - the mean difference was: in men $24.85 \pm 37.82$ $\mathrm{kcal} /$ day $(p=0.0002)$, in women $6.27 \pm 17.88 \mathrm{kcal} /$ day $(p=0.0233)$. Also, the RMR value determined using the body composition analysis decreased significantly as a result of surgical trauma: in men the difference was $60.75 \pm 85.47 \mathrm{kcal} /$ day $(p=0.0001)$ and in women $64.67 \pm 57.78 \mathrm{kcal} /$ day $(p<0.0001)$.

The RMR was measured by means of indirect calorimetry (IC) method with a prediction value calculated using the $\mathrm{HB}$ formula and the value obtained from the body composition analysis using the bioelectric impedance method (BIA). In women, RMR values calculated from the HB formula (before surgery: $1335.67 \pm 130.54$ $\mathrm{kcal} /$ day, after surgery: $1339.40 \pm 126.00 \mathrm{kcal} /$ day) and obtained from BIA analysis (before operation: 1383.56 $\pm 97.82 \mathrm{kcal} /$ day, after surgery: $1318.89 \pm 86.50 \mathrm{kcal} /$ day) were significantly higher than the measured IC. In men, the differences, where the reference point was indirect calorimetry, were not statistically significant (Figure 1). After checking with the Friedman ANOVA test, the RMR results were significantly differentiated by the sex of patients, higher in males $(p<0.0001)$.

The median RMR after standardisation determined by IC method before surgery was $18.95 \mathrm{kcal} / \mathrm{kg} / \mathrm{day}$ (min.: 13.31, max.: 28.11) and did not change noticeably after surgery $(p=0.6892, M=18.98 \mathrm{kcal} / \mathrm{kg} / \mathrm{day}$, min.: 13.63, max.: 27.80). In the group of women, the mean standardised preoperative value was 18.29 $\pm 2.27 \mathrm{kcal} / \mathrm{kg} /$ day; after surgery it increased slightly by $0.57 \pm 2.67 \mathrm{kcal} / \mathrm{kg} /$ day. However, in the group of men there was a slight decrease (by $0.39 \pm 3.10 \mathrm{kcal} /$ $\mathrm{kg} /$ day) compared to the average preoperative value of $20.07 \pm 3.29 \mathrm{kcal} / \mathrm{kg} /$ day. Standardised values for body weight are shown in Figure 2.

Significant differences between the methods were noted in the case of standardised, pre-operative RMR determined by the IC method, relative to the result calculated from the HB formula (difference 0.83 $\pm 2.49 \mathrm{kcal} / \mathrm{kg} /$ day, $p=0.0005$ ) and the amount determined from BIA (difference $1.24 \pm 2.90 \mathrm{kcal} / \mathrm{kg} /$ day, $p=0.0001$ ). After the operation, only the standardised $\mathrm{IC}$ values against $\mathrm{HB}$ were significantly different (difference $0.81 \pm 2.13 \mathrm{kcal} / \mathrm{kg} /$ day, $p=0.0007$ ). After checking with the Friedman ANOVA test of standardised energy demand factors for sex, statistical significance was demonstrated for one pair of variables: RMR measured for IC before surgery $(p=0.0075)$ - the mean value in women was equal to $18.29 \pm 2.27 \mathrm{kcal} / \mathrm{kg} /$ day, and in men $20.07 \pm 3.29 \mathrm{kcal} / \mathrm{kg} /$ day.

Data regarding differences in energy demand determined by indirect calorimetry method were analysed by Friedman test due to the type of surgery performed. It was shown that the type of surgery had a significant effect $(p=0.0102)$ on the change in resting metabolism: segmentectomies (+82.2 kcal/day) and resection of lesions (+77.74 kcal/day) contribute to the increase in RMR, and extended resection of lesions $(-126.5 \mathrm{kcal} / \mathrm{day})$, hemihepatectomies - both broadened $(-128 \mathrm{kcal} /$ day $)$ and simple $(-95.5 \mathrm{kcal} /$ day), thermoablation $(-76.5 \mathrm{kcal} /$ day), as well as segmented metabolites ( $-45.2 \mathrm{kcal} /$ day) cause a decrease in metabolism (Figure 3 ).

Selected data from anthropometric measurements and body composition analyses collected during the 
Table I. Comparison of values obtained from body composition analysis $(n=87)$

\begin{tabular}{|c|c|c|c|c|c|c|c|c|c|c|c|c|c|}
\hline \multirow[t]{2}{*}{ Parameter } & \multicolumn{4}{|c|}{ General } & \multicolumn{4}{|c|}{ Males } & \multicolumn{4}{|c|}{ Females } & \multirow[t]{2}{*}{ Unit } \\
\hline & $\begin{array}{c}\text { Mean } \\
\pm \text { SD }\end{array}$ & Median & Difference & $P$-value & $\begin{array}{c}\text { Mean } \\
\pm S D\end{array}$ & Median & Difference & $P$-value & $\begin{array}{c}\text { Mean } \\
\pm \text { SD }\end{array}$ & Median & Difference & $P$-value & \\
\hline PA1 & $\begin{array}{c}5.20 \\
\pm 0.87\end{array}$ & 5.3 & \multirow[t]{2}{*}{-0.68} & \multirow[t]{2}{*}{$<0.001$} & $\begin{array}{c}5.37 \\
\pm 1.03\end{array}$ & 5.45 & \multirow[t]{2}{*}{-0.56} & \multirow[t]{2}{*}{$<0.001$} & $\begin{array}{c}5.05 \\
\pm 0.67\end{array}$ & 5 & \multirow[t]{2}{*}{-0.78} & \multirow[t]{2}{*}{$<0.001$} & \multirow[t]{2}{*}{$\circ$} \\
\hline PA2 & $\begin{array}{c}4.55 \\
\pm 0.89\end{array}$ & & & & $\begin{array}{c}4.81 \\
\pm 0.95\end{array}$ & & & & $\begin{array}{c}4.30 \\
\pm 0.76\end{array}$ & & & & \\
\hline TBW1 & $\begin{array}{r}40.83 \\
\pm 8.85\end{array}$ & 39.95 & \multirow[t]{2}{*}{0.52} & \multirow[t]{2}{*}{0.180} & $\begin{array}{l}48.75 \\
\pm 5.59\end{array}$ & & \multirow[t]{2}{*}{0.23} & \multirow[t]{2}{*}{0.703} & $\begin{array}{l}33.94 \\
\pm 4.07\end{array}$ & 32.9 & \multirow[t]{2}{*}{0.78} & \multirow[t]{2}{*}{0.096} & \multirow[t]{2}{*}{1} \\
\hline TBW2 & $\begin{array}{r}41.53 \\
\pm 8.64\end{array}$ & 40.4 & & & $\begin{array}{l}48.98 \\
\pm 5.41\end{array}$ & & & & $\begin{array}{l}34.66 \\
\pm 4.07\end{array}$ & & & & \\
\hline ECW1 & $\begin{array}{l}20.34 \\
\pm 4.87\end{array}$ & 20 & \multirow[t]{2}{*}{1.95} & \multirow[t]{2}{*}{$<0.001$} & $\begin{array}{l}24.07 \\
\pm 4.10\end{array}$ & & \multirow[t]{2}{*}{1.72} & \multirow[t]{2}{*}{$<0.001$} & $\begin{array}{c}17.11 \\
\pm 2.67\end{array}$ & 16.4 & \multirow[t]{2}{*}{2.16} & \multirow[t]{2}{*}{$<0.001$} & \multirow[t]{2}{*}{1} \\
\hline ECW2 & $\begin{array}{l}22.38 \\
\pm 4.91\end{array}$ & 22.05 & & & $\begin{array}{l}25.78 \\
\pm 4.21\end{array}$ & & & & $\begin{array}{l}19.28 \\
\pm 3.20\end{array}$ & 18.6 & & & \\
\hline ICW1 & $\begin{array}{l}20.59 \\
\pm 5.07\end{array}$ & 19.45 & \multirow[t]{2}{*}{-1.54} & \multirow[t]{2}{*}{$<0.001$} & $\begin{array}{l}24.68 \\
\pm 4.13\end{array}$ & & \multirow[t]{2}{*}{-1.48} & \multirow[t]{2}{*}{$<0.001$} & $\begin{array}{l}16.98 \\
\pm 2.41\end{array}$ & & \multirow[t]{2}{*}{-1.59} & \multirow[t]{2}{*}{$<0.001$} & \multirow[t]{2}{*}{1} \\
\hline ICW2 & $\begin{array}{l}19.15 \\
\pm 5.07\end{array}$ & 18 & & & $\begin{array}{l}23.20 \\
\pm 3.95\end{array}$ & & & & $\begin{array}{l}15.37 \\
\pm 2.34\end{array}$ & & & & \\
\hline FFM1 & $\begin{array}{r}53.09 \\
\pm 11.23\end{array}$ & 50.9 & 0.49 & 0.224 & $\begin{array}{l}62.81 \\
\pm 7.94\end{array}$ & & 0.23 & 0.762 & $\begin{array}{l}44.59 \\
\pm 0.17\end{array}$ & & 0.71 & 0.108 & kg \\
\hline FFM2 & $\begin{array}{r}53.80 \\
\pm 10.81\end{array}$ & 52.4 & & & $\begin{array}{l}63.04 \\
\pm 7.08\end{array}$ & & & & $\begin{array}{l}45.30 \\
\pm 5.15\end{array}$ & & & & \\
\hline $\mathrm{BCM} 1$ & $\begin{array}{l}26.35 \\
\pm 6.63\end{array}$ & 24.65 & -2.22 & $<0.001$ & $\begin{array}{l}31.46 \\
\pm 5.71\end{array}$ & & -2.24 & $<0.001$ & $\begin{array}{l}21.92 \\
\pm 3.40\end{array}$ & & -2.20 & $<0.001$ & kg \\
\hline $\mathrm{BCM} 2$ & $\begin{array}{l}24.25 \\
\pm 6.46\end{array}$ & 22.7 & & & $\begin{array}{l}29.22 \\
\pm 5.39\end{array}$ & & & & $\begin{array}{l}19.64 \\
\pm 2.96\end{array}$ & & & & \\
\hline MM1 & $\begin{array}{l}32.90 \\
\pm 8.07\end{array}$ & 30.7 & -2.07 & $<0.001$ & $\begin{array}{l}39.35 \\
\pm 6.47\end{array}$ & & -2.16 & $<0.001$ & $\begin{array}{l}27.29 \\
\pm 4.18\end{array}$ & 27 & -1.99 & $<0.001$ & kg \\
\hline MM2 & $\begin{array}{l}30.97 \\
\pm 7.71\end{array}$ & 28.65 & & & $\begin{array}{l}37.20 \\
\pm 5.98\end{array}$ & & & & $\begin{array}{l}25.20 \\
\pm 3.38\end{array}$ & & & & \\
\hline FM1 & $\begin{array}{l}23.26 \\
\pm 9.93\end{array}$ & 22.5 & -1.72 & $<0.001$ & $\begin{array}{r}22.80 \\
\pm 11.28\end{array}$ & & -2.13 & $<0.001$ & $\begin{array}{l}23.97 \\
\pm 9.59\end{array}$ & & -1.36 & $<0.001$ & kg \\
\hline FM2 & $\begin{array}{c}21.73 \\
\pm 10.15\end{array}$ & 20.55 & & & $\begin{array}{l}20.67 \\
\pm 11.10\end{array}$ & & & & $\begin{array}{l}22.62 \\
\pm 9.38\end{array}$ & & & & \\
\hline
\end{tabular}

XX1-for measurements before the surgery, XX2 - for measurements after the surgery; Student's t-test results for two variables with normal distribution are marked in italics. The median value was given for data with a distribution different from normal.

research were correlated with the results of energy demand. The length of the arm circumference measured in the pre-operative procedure was compared with the resting metabolism obtained with IC; a fairly good positive correlation was demonstrated - for the first measurement: $r 1=0.6163$, and for the second postoperative measurement: $r 2=0.5943$ - the results are statistically significant for the constructed regression model ( $p<$ 0.001 ). Standardised coefficients show a weaker, negative relation to the arm's circumference: $r 1=-0.4048$; $r 2=-0.4907$. A relatively high degree of correlation was also obtained for the association with WHR: $r 1=$ $0.6447 ; r 2=0.5688$. From the body composition data, strong correlations were demonstrated for the following parameters: lean body mass $(r 1=0.8001, r 2=0.7312)$, muscle mass $(r 1=0.7745, r 2=0.7687)$, and cell mass $(r 1=0.7448 ; r 2=0.7571)$. There were no significant relationships for standardised coefficients.

\section{Discussion}

The anthropometric measurements and analyses of both the composition of the body and the resting metabolic rate in the study group indicate that initially patients were in good general condition, and there were no signs of malnutrition in this group; however, the problem of excessive body mass is noticeable (BMI $\left.\geq 25 \mathrm{~kg} / \mathrm{m}^{2}\right)$ in 


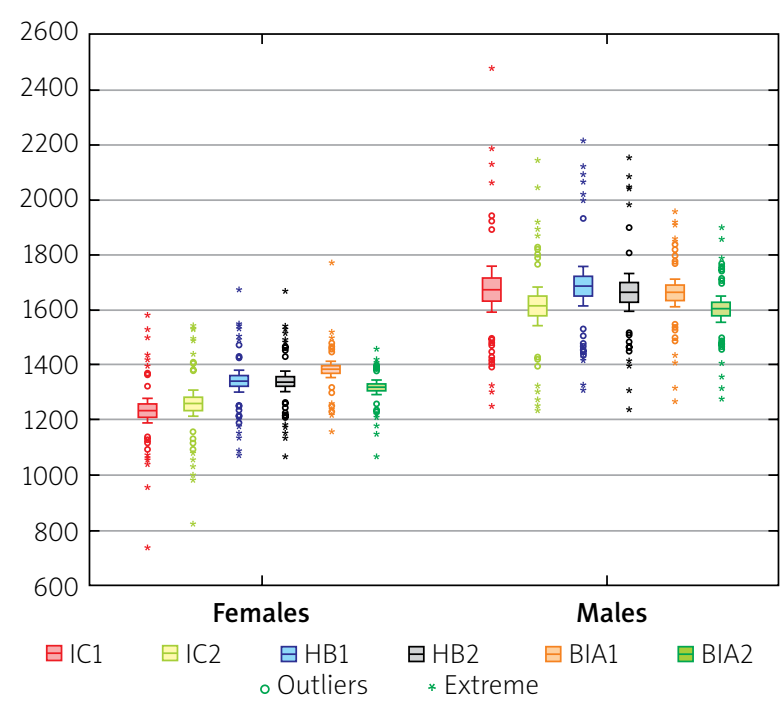

Figure 1. Comparison of the amount of resting metabolism in $\mathrm{kcal} /$ day in the study group $(n=87)$

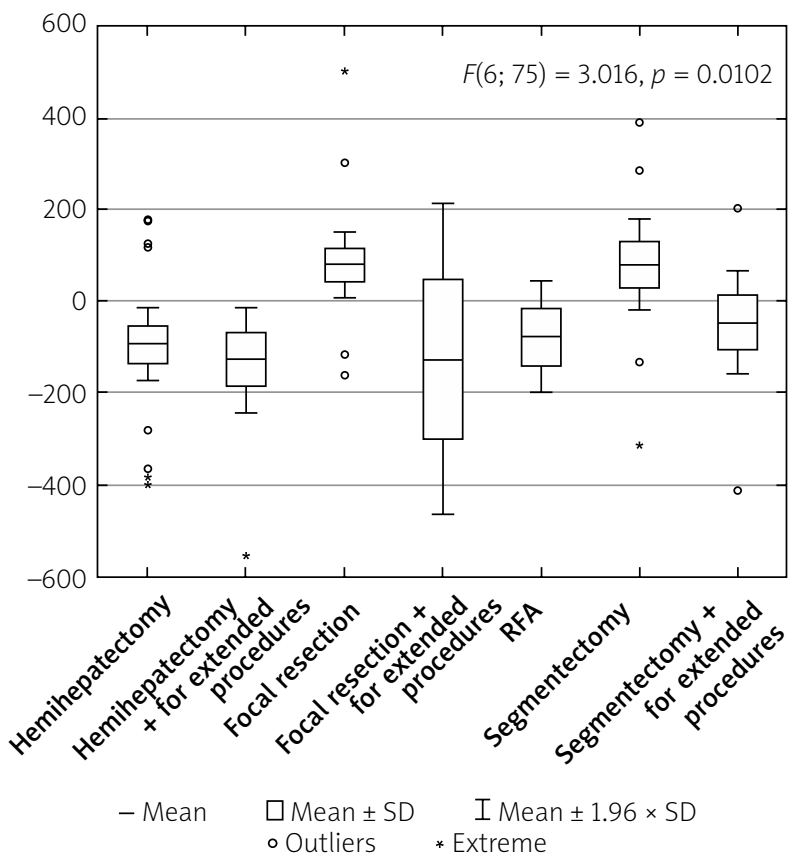

Figure 3. Comparison of average differences in resting metabolic rates in $\mathrm{kcal} /$ day due to the type of resection procedure used in the study group $(n=87)$

$67 \%$ of respondents. The occurrence of overweight and obesity is a confirmed risk factor for many cancers, especially cancers that develop within the digestive system, such as colon adenocarcinoma [5-7].

Bioimpendance is a safe and non-invasive method that can be used for pre-operative assessment of patients, which gives a reference assessment of the body's

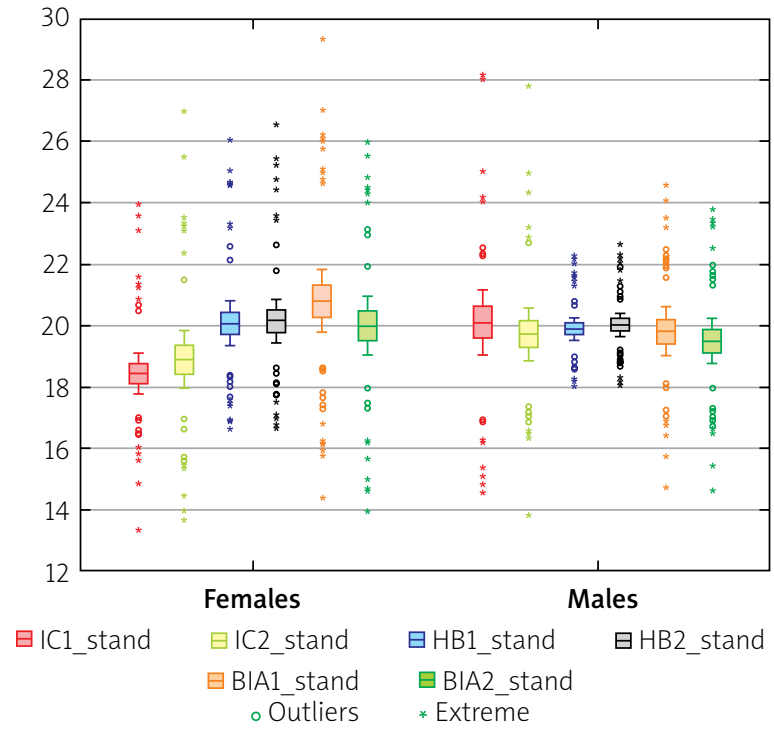

Figure 2. Comparison of standardised basal metabolic rates in the study group due to the current body mass $(n=87)$

water compartments. One of the indicators obtained by the bioelectrical impedance method is the phase angle, which is the physical size of the capacitive resistance produced mainly by cellular membranes, also called reactance. The value of the phase angle is essentially related to the degree of integrity of the cell membranes, the amount of cell mass, muscle mass, and fat-free mass. After the surgery, during hospitalisation in the ward, the vast majority of respondents reduced the phase angle value, which probably results from the surgical procedure used, the perioperative period of fasting, fluid therapy, and the individual catabolic reaction of the body to injury [8-11].

The BIA measurement technique used in the test procedure using the octapolar connection to the device is suitable for assessing changes in individual body segments and identifying fluid accumulation in the spaces. The decrease in the phase angle values observed in the studied group also involves changes in the body's water compartments - the displacement of water from the intracellular space to the extracellular space. Such a tendency may be indicative of the transient occurrence of body cavities, which in the interpretation of these changes should take into account the supply of fluids in the perioperative period, which is often excessive and should be optimised [8-11].

Significant reduction of cellular mass, muscle mass, and fat mass in patients after surgery may be partially caused by: removal of pathological changes and resulting cell damage, perioperative immobilisation period, immune and regenerative reactions in response to in- 
jury, interruption in the supply of nutrients, temporary overhydration, as well as the accuracy and precision of the measurement method used [3]. The reduction in cellular mass and muscle mass in the study group did not translate into a change in lean body mass, which statistically increased in a statistically insignificant manner. The fat mass changed significantly in patients, dropping by more than $1.5 \mathrm{~kg}$ on average. The absolute amount of adipose tissue is not differentiated by gender; however, its percentage is higher in women compared to men (males: $25.8 \%$; females: $33.7 \%, p<$ 0.0001 ). Changes in FFM and mass of fat, which is the total body weight, after the summation show a downward trend, on average by $1.23 \mathrm{~kg}$, while the average body weight decreased by $0.78 \mathrm{~kg}$; due to the standard deviation values, it can be assumed that the bioelectric impedance correctly displays the state of patients.

Changes in resting metabolism due to surgery were assessed using the indirect calorimetry method, as well as through the use of the Harris-Benedict formula and the result obtained from BIA. The value of indirect calorimetry, considered the gold standard for the assessment of energy expenditure, was taken as a reference point for the remaining methods. The use of indirect calorimetry is non-invasive and consists of the analysis of gases: taken during breathing oxygen and/or exhaled carbon dioxide. The measured gas volumes are used to calculate the resting metabolic rate using a simplified version of the Weir equation [12].

The study showed no unequivocal effect of partial resection of the liver on the value of the resting metabolic rate obtained from the IC measurement. Similar assumptions were made in the study by Hughes et al. in which the differences in energy expenditure measured using the SenseWear armband clamped device, which was validated against the GEMnutrition, UK calorimeter, were checked. Twenty-one IC measurements were performed before operation - the standardised value was $20.6 \mathrm{kcal} / \mathrm{kg}$ - and 19 measurements after surgery, the median of which was equal to $22.2 \mathrm{kcal} / \mathrm{kg}$. The predictive values based on the HB formula were significantly lower than the measured values. The authors of the study found that higher postoperative energy expenditure was associated with older age (median age: 64 years) and longer operation time (median: $216 \mathrm{~min}$ ) [13]. In the study, lower standardised values were obtained (before the operation the median was: $18.95 \mathrm{kcal} / \mathrm{kg}$, and after the operation: $18.98 \mathrm{kcal} / \mathrm{kg}$ ), while in relation to the standardisation of the result calculated from the Harris-Benedict formula, the results were higher than those measured using indirect calorimetry $(19.96 \mathrm{kcal} / \mathrm{kg}$ before and $20.05 \mathrm{kcal} / \mathrm{kg}$ after the procedure). The median age in the study group was similar (63 years), while the median time of surgery was lower and amounted to $150 \mathrm{~min}$.

In a study by Sugihara et al. the change in the percentage of resting energy expenditure (REE) in the seventh and $14^{\text {th }}$ postoperative days in 18 hepatocellular carcinoma (HCC) patients undergoing partial resection of the liver, including 15 men and 3 women (mean age: 67 years, BMI $22.3 \mathrm{~kg} / \mathrm{m}^{2}$ ), was checked. For the first measurement performed 1 week after surgery, a reduction in the percentage of REE was observed, while after 2 weeks of hospitalisation, the value was higher than the pre-operative value; however, these results were not statistically significant. Lack of statistical significance for the trends was also observed in a study conducted by Wada et al. in patients with oncological liver surgery, which is consistent with the results of our own research $[14,15]$.

The amount of energy expenditure is largely affected by: lean body mass, cell mass, and muscle mass, which are the basis for the determination of RMR using the BIA method. In a study by Pinto et al. among patients after liver transplantation, the average value was $1584 \pm 377 \mathrm{kcal} /$ day and was higher by an average of $50 \mathrm{kcal}$ from the result obtained by indirect calorimetry: $1534 \pm 300 \mathrm{kcal} /$ day [16]. In the performed study, the average preoperative value for the energy demand determined by the BIA method was $1515 \pm 193 \mathrm{kcal} /$ day. It was also higher than the amount obtained by IC on average by $81 \mathrm{kcal}(1434 \pm 302 \mathrm{kcal} /$ day $)$. This indicates a fairly similar, slight degree of deviation in the estimation of energy demand in the analysed groups.

The extent of the surgery performed has an effect on the amount of changes in metabolism. The wide range of hemihepatectomies consisting of the removal of the whole lobe of the liver, i.e. at least four functional segments of this organ, contributes to the largest reduction in metabolic rate, as in the performance of expanded segmentectomies in which at least two segments have been removed, as well as resection of outbreaks in other organ sectors. Thermoablation of lesions, as well as resections of focal lesions extended with thermoablation, also contributed to the reduction of RMR; however, due to the small group of patients in whom such procedures were performed, confidence in this result should be limited. Operations with a narrower scope, i.e. focal lesions as well as exclusive segmentectomies in the test group, cause an increase in metabolic changes. The interpretation of this observation is not unambiguous; it would be reasonable to determine the safe range of left-behind, functionally active liver parenchyma, in order to reduce the intervention of the procedure in the systemic metabolism. 
The obtained high degree of correlation between the selected anthropometric measurements (arm circumference and WHR) and the resting metabolic rate measured with IC may be the basis for the construction of a prediction equation for estimating energy demand for people with a similar clinical situation. Carrying out anthropometric measurements is easy and does not require the use of specialised equipment, and it can be implemented in a routine procedure. This type of action has already been taken among other groups: patients with cirrhosis [17] and with ischaemic heart disease [18], in whom significant relationships have also been confirmed.

\section{Conclusions}

Surgical resection of neoplastic lesions or their thermoablation aimed at extending patient survival are performed more and more often, while the consequences of these operations are not sufficiently known. The adverse effect of resection treatments on body composition parameters, mainly imaged by decreasing the phase angle value, should be minimised. Effects on metabolism remain ambiguous, because no significant changes have been demonstrated in the postoperative period. It is necessary to continue the research both in terms of looking for prognostic factors and determining a new technique for determining the metabolic status for this group of patients and achieving greater precision of the obtained results.

\section{Conflict of interest}

The authors declare no conflict of interest.

\section{References}

1. Torre LA, Bray F, Siegel RL, et al. Global Cancer Statistics, 2012. CA Cancer J Clin 2015; 65: 97-9.

2. Scalori A, Tavani A, Gallus S, et al. Oral contraceptives and the risk of focal nodular hyperplasia of the liver: a case-control study, Am J Obstet Gynecol 2002; 186: 195-7.

3. Mellou E, Hubner M, Scott M, et al. Guidelines for perioperative care for liver surgery: Enhanced Recovery After Surgery (ERAS) Society Recommendations. World J Surg 2016; 40: 2425-40.

4. Ferlay J, Soerjomataram I, Ervik M, et al. GLOBOCAN 2012 v1.0, Cancer Incidence and Mortality Worldwide: IARC CancerBase No. 11 [Internet]. Lyon, France: International Agency for Research on Cancer; 2013. Available from: http://globocan.iarc. fr, accessed on 21/08/2018

5. Tandon K, Imam M, Ismail BES, et al. Body mass index and colon cancer screening: the road ahead. World J Gastroenterol 2015; 21: 1371-6.

6. Omata F, Brown RW, Tokuda Y, et al. Modifiable risk factors for colorectal neoplasms and hyperplastic polyps. Intern Med 2008; 48: 123-8.
7. Takahashi H, Hosono K, Endo H, et al. Colon epithelial proliferation and carcinogenesis in diet-induced obesity. J Gastroenterol Hepatol 2013; 28: 41-7.

8. Kyle UG, Ingvar Bosaeus I, De Lorenzo AD, et al. Bioelectrical impedance analysis - part I: review of principles and methods. Clin Nutr 2004; 23: 1226-43.

9. Kyle UG, Ingvar Bosaeus I, De Lorenzo AD, et al. Bioelectrical impedance analysis - part II: utilization in clinical practice. Clin Nutr 2004; 23: 1430-53.

10. Savegnago Mialich M, Faccioli Sicchieri JM, Jordao Junior AA. Analysis of body composition: a critical review of the use of bioelectrical impedance analysis. Int J Clin Nutr 2014, 2: 1-10.

11. Norman K, Stobäus N, Pirlich M, et al. Bioelectrical phase angle and impedance vector analysis - clinical relevance and applicability of impedance parameters. Clin Nutr 2012; 31: 854-61.

12. Oshima T, Berger MM, De Waele E, et al. Indirect calorimetry in nutritional therapy. A position paper by the ICALIC study group. Clin Nutr 2017; 36: 651-62.

13. Hughes MJ, Harrison EM, Wigmore SJ. Energy expenditure after liver resection: validation of a mobile device for estimating resting energy expenditure and an investigation of energy expenditure change after liver resection. J Parenteral Enteral Nutr 2017; 41: 766-75.

14. Sugihara K, Yamanaka-Okumura H, Teramoto A, et al. Recovery pattern of non-protein respiratory quotient and non-esterified fatty acids after liver resection. Nutrition 2014; 30: 443-8.

15. Wada S, Yamanaka-Okumura H, Katayama T, et al. Major liver resection reduces nonprotein respiratory quotient and increases nonesterified fatty acid at postoperative day 14 in patients with hepatocellular carcinoma. Clin Nutr ESPEN 2018; 23: 194-9.

16. Pinto AS, Chedid MF, Guerra LT. Estimating basal energy expenditure in liver transplant recipients: the value of the Harris-Benedict equation. Arq Bras Cir Dig 2016; 29: 185-8.

17. Terakura Y, Shiraki M, Nishimura K, et al. Indirect calorimetry and anthropometry to estimate energy metabolism in patients with liver cirrhosis. J Nutr Sci Vitaminol 2010; 56: 372-9.

18. Taggart DP, McMillan DC, Preston T, et al. Resting and total energy expenditure in patients with ischemic heart disease. Nutrition 1991; 7: 271-4.

Received: 9.10.2018

Accepted: 12.11 .2018 